\title{
Technologies of Working on Graphic Materials in Fine Arts Classes
}

\author{
Ismatov Ulfat Shuhratovich \\ *Corresponding Email: ulfat.shuhratovich@ gmail.com \\ Chirchik State Pedagogical Institute of Tashkent region \\ Teacher of the Department of Fine Arts Ismatov U.Sh.
}

Received: October 25, 2020

Revised: November 2, 2020

Accepted: November 4, 2020

\begin{abstract}
This article discuses technology used to develop graphic material in fine arts classes. The purpose of fine arts classes is to teach students to draw on a variety of graphic materials; to teach them to see, comprehend, understand and appreciate the beauties of being and art; to develop aesthetic and artistic taste, to expand the scope of artistic thought; to develop artistic creativity and imagination, to help them find their own style, their own way of creativity.
\end{abstract}

Keywords: Watercolor, Gouache, Creation

\section{Introduction}

There are many types of graphic materials in the visual arts classes of higher pedagogical education today, and each creative artist has his or her own style, imaging techniques, and materials used in the process of creating a work. Some like to paint with watercolors, others like to paint with gouache or watercolors, and still others like to paint with pencil, retouch, acrylic paint, sangina and other materials.

Fine art means a work of art is made only for the purpose of beauty without considering its use (Benjamin, 2009; Butcher \& Gassner, 1951). for example painting, sculpture, etc. while the opposite of fine art is applied art. that is, art that, apart from considering aesthetics, is also made to be used for its benefits. for example carving door frames, ashtrays, etc.

The notion of graphics is a visual design on the surface of an object, for example a wall, canvas, paper, to provide information or a picture (Dumesny \& Fouts, 2002). Examples of graphics include photographs, drawings, line art, graphics, diagrams, typography, numbers, symbols, geometric designs, maps, technical drawings, or other images. Whereas computer graphics are any image media, usually films and images, created through the use of hardware and software. Often referred to as computer generated images; better known as CGI. Graphics can be functional or artistic. Graphics can also be recorded versions, such as photographs, or interpretations by a scientist to highlight important features, or an artist (Arntson, 2011).

In the fine arts, the experience gained from working with watercolors plays an important role in the success of paintings. Because the more carefully you work with paint, the better your color images will be. Other artists may leave small details of aesthetic value to suit client wants or market needs. While fine artists don't have to, even though fine art will eventually create its own market. In essence, if the artist wishes, he can completely abandon all commercial aspects and the benefits of the work he creates.

\section{Limits of Fine Arts}

However, that does not mean that a pure artist can arbitrarily create objects that he thinks are art. To the layman, some pure artists may seem like that. In fact, there are many challenges one must face when creating works of fine art (Markovich \& Rapoport, 2013). 
Fine art works must get recognition from art world activists who will appreciate, study and criticize works of art. The activists of the art world include: art critics, academics, curators, gallery owners, other fine artists, to collectors who will buy their work. In fact, the general public is also a part of the social circle of art, but a pure artist can ignore one or two, even all circles of the art field.

\section{Fine Art Learning}

In learning fine arts, the roles of fine arts, crafts, and design are complementary and interrelated. Fine arts learning can be done with a studio approach, for example, painting studios, sculpture, printmaking, and crafts. Fine arts learning can also be separated into activities of learning fine arts, crafts, and design (Kandiuk \& Lupton, 2012)

The main subjects of fine arts include aspects of art appreciation, art work, art criticism, and art presentation. Appreciation of art means knowing, understanding, and giving appreciation or an aesthetic response (an aesthetic response) to a work of art. Art appreciation material is basically an introduction to the concept or meaning, form, and function of art. Appreciation of art can cover a broader range of materials, namely the introduction of art in the context of various cultures (Beane, 1989).

The subject matter of art appreciation in Elementary and Secondary education includes an introduction to local culture, other regional cultures, and foreign cultures, both primitive, traditional, classical, modern, and contemporary. In addition to the introduction of fine art forms, the material of appreciation also includes an introduction to the social, cultural and historical backgrounds in which art works are produced and the meanings and values of these fine arts.

The discussion of the concept of art includes the structure of forms and expressions (expressions) in pure art and the relationship between forms, functions and aesthetic elements in applied art. The discussion of art media includes the characteristics of the media, the process, and the techniques for making fine art works. Apart from that, art appreciation also needs to provide an understanding of the relationship between art and other art forms, other fields of study, as well as the existence of art, crafts, and design as professional fields.

\section{Main Point}

When using watercolors, it is important to pay attention to their quality. It is recommended to mix the paints with water in special containers and test them on a piece of paper. It should only be used when the color found has reached the desired level. To master the technique of working with watercolors, you need to practice the initial exercises to create different shades of black or dark brown from the same color as the pencil. Working in this way is called working in monochrome or grizzly method.

Grizzly painting is a preparation step before moving on to using different colors (Feder \& Chandler, 2016). It provides an opportunity to learn how to use a brush and the properties of watercolors. After studying a few still lives in the Grizzly technique, it will be much easier to create a still life using all the colors.

Paintings can only meet the requirements if the following sequence is followed when working with watercolors. The next coat of paint will not be applied until the paint on the base coat has dried. The next layer should be applied quickly otherwise the bottom layer may be washed away. White paint is not used when working with watercolors, because the white paper itself acts as a white paint. The surface of the paper should be visible under the layer of paint. 


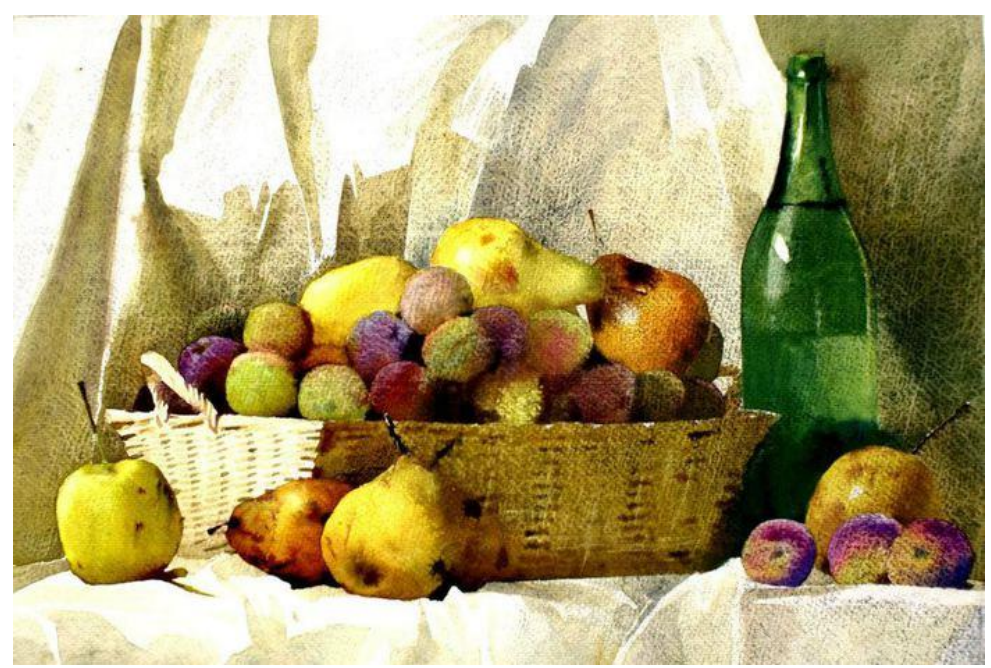

Practical training is very important in learning to work with watercolors. For example, let's take the practice of putting one color on top of another to create a new color. The surface of the paper should be visible under both colors. Also a warm hue over a cool hue, or a warm hue It is necessary to carefully study the ways of creating a new color by covering it with a cool color.

In some cases, it is recommended to cover the colors with a liquid, weak solution of one color to equalize the light levels. Keep in mind that when a certain color is overlaid with another color, it loses its reflective properties. However, the level of clarity and saturation of the previous layer of paint is important. The top layer should always be toned, very clear and should not obscure the color of the bottom.

Gouache, on the other hand, is the exact opposite of watercolor and does not look as clear and vibrant as it used to be. Because the colors absorb light, the paper underneath is invisible. The composition is similar to watercolors - paint powder and its binders. However, they are mixed with a special wood glue in moderate proportions. Another important feature of gouache is that it can be mixed with white paint.

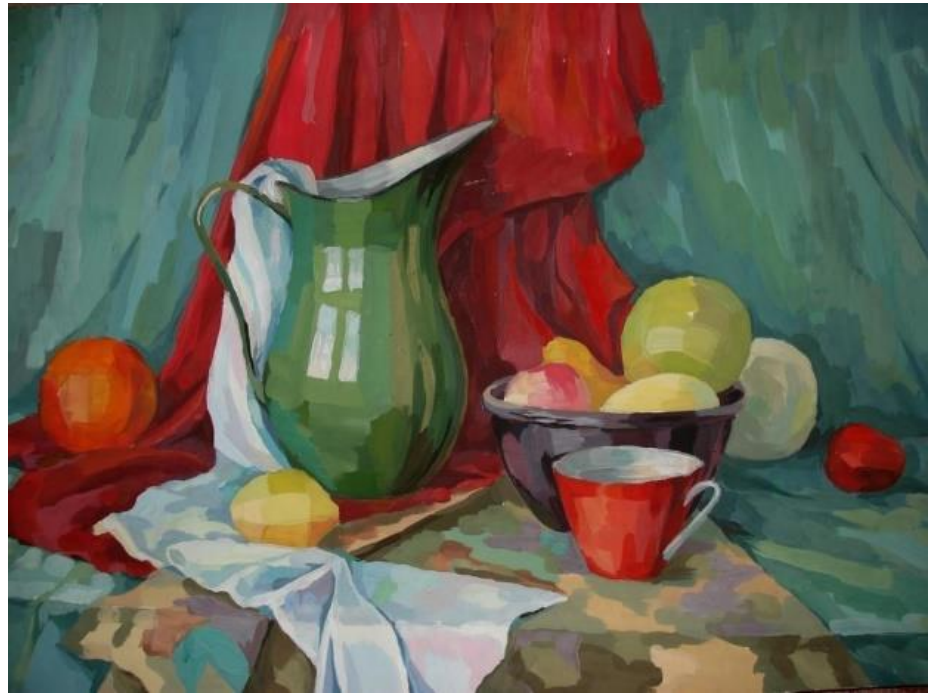

That's why its colors don't resonate so much. Brushes are also specially selected for the use of paint, and it is advisable that they are not too soft, but a little rougher. It is good that the surface on which the image is processed, i.e. paper or cardboard, is also not slippery. Its surface should be treated with an adhesive coating (primer) as much as possible. Then you can apply gouache on the surface. Gouache is a fast-drying paint that is often used in the processing of graphic works, decorations, posters, and partially in the performance of color images. Images with it 
the complexity of the performance is that the paint is dark when applied and looks hungry after drying. If this aspect is not taken into account, it will be much more difficult to maintain compatibility between colors. To do this, usually the primary colors of each paint are prepared in separate special containers, and then the image is processed by mixing a few other additives to it. When using colors, it is advisable to always check the darkness of the color, how to find the color shades, to rub the mixture prepared on a piece of paper to find out, and then apply it.

It is known that many artists of the past have created works of gouache. Their magnificent still lifes, landscapes, theatrical decorations, portraits, posters are among the treasures of world fine arts. However, it is no secret that some of these delicate, difficult-to-maintain works, especially those that are thick, have faded and need to be repaired. When painting with gouache, it is best to use a separate brush for each color, if possible. Then the colors will be clear and clean, attractive. It's hard to paint with gouache, especially portraits and human body parts, to give it a subtle glow. It will take a lot of skill, knowledge, experience. The guidance and thorough mastery of image processing is a process that requires a lot of practical. It is convenient to make sketches of large monumental works and composition projects, as well as holiday photos on gouache. With it, comprehensive, majestic images are quickly processed.

\section{Conclusion}

In short, one of the main goals of every higher education institution today is to teach modern fine arts teachers the properties and techniques of working with a variety of graphic materials, particularly gouache; to teach them to see, comprehend, understand and appreciate the beauties of being and art; to develop aesthetic and artistic taste, to expand the scope of artistic thought; to develop artistic creativity and imagination, to help them find their own style, way of creation, as well as to train experienced, mature personnel in the field of fine arts education.

\section{References}

Arntson, A. E. (2011). Graphic design basics. Cengage Learning.

Beane, M. B. (1989). Focus on Fine Arts: Performing Arts. NEA Professional Library, PO Box 509, West Haven, CT 06516.

Benjamin, W. (2009). The work of art in the age of mechanical reproduction. Media and cultural studies: KeyWorks, 2nd edn, Blackwell, Malden, 18-40.

Butcher, S. H., \& Gassner, J. (1951). Aristotle's theory of poetry and fine art: with a critical text and translation of the Poetics. With a prefatory essay, Aristotelian literary criticism (Vol. 42). Courier Corporation.

Dumesny, A. M., \& Fouts, C. L. (2002). U.S. Patent Application No. 08/903,440.

Feder, N., \& Chandler, M. G. (2016). Grizzly claw necklaces. Whispering Wind, 44(2), 9.

Kandiuk, M., \& Lupton, A. (2012). Digital images in teaching and learning at York University: Are the libraries meeting the needs of faculty members in fine arts?. Evidence Based Library and Information Practice, 7(2), 20-48.

Markovich, D. Y., \& Rapoport, T. (2013). Creating art, creating identity: Under-privileged pupils in art education challenge critical pedagogy practices. International Journal of Education through Art, 9(1), 7-22. 